Editor's Note

The year 2020 marks the 25th anniversary of the Journal of Managed Care E Specialty Pharmacy. To commemorate this milestone, we are publishing a series of articles that document the changes to the journal and profession over the past 2 and a half decades. Each month we reprint an original article from a previous year, dating back to 1995. The reprinted articles feature topics of significance in our industry. Each reprinted article is accompanied by a contemporary reflection that will consider the historical significance of the topic, as well as the current and future state.

Laura E. Happe, PharmD, MPH

Editor-in-Chief

\title{
Twenty Years of Experience and Counting: Strategies for Growing Medication Therapy Management Services
}

\section{Amanda R. Brummel, PharmD, BCACP, and Todd D. Sorensen, PharmD}

W hen the article "Medication Therapy Management: 10 Years of Experience in a Large Integrated Health Care System" was published in 2010, ${ }^{1}$ the intent was to provide a comprehensive overview of the Fairview Health System's medication management program and the various factors that were contributing to its viability and sus-

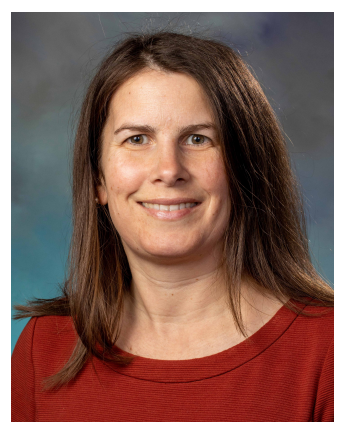
tainability. These factors included an environmental element (payment opportunities in the market); operational elements (adoption of a clear and specific practice model, staff training expectations, and quality assurance processes); and program evaluation (practice metrics, clinical and economic outcomes, and patient satisfaction). It was hoped that sharing this comprehensive program design would provide inspiration and direction for pharmacy leaders to drive growth of these services locally and nationally, increasing the opportunity for pharmacists to positively affect patient health and the costs associated with health care. Now, 10 years later, it is relevant to reflect on the status of this goal. We direct these reflections at 3 levels: current program status within

J Manag Care Spec Pharm. 2020;26(9):1067-70

Copyright $\odot 2020$, Academy of Managed Care Pharmacy. All rights reserved.

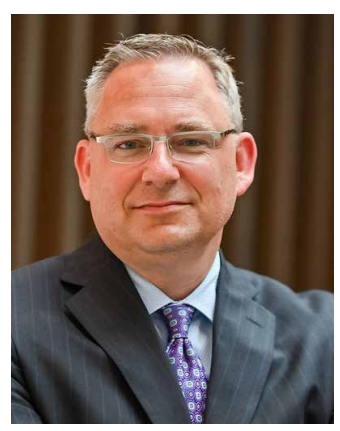

M Health Fairview, adoption in the state of Minnesota, and uptake nationally.

\section{Current Program Status}

Since 2010, many things have changed and yet stayed the same at Fairview Health Services. As a system, Fairview has grown through mergers and partnerships. Currently, Fairview Health Services, now branded $M$ Health Fairview, includes 12 hospitals and 56 primary care clinics with over 100 specialties in collaboration with the University of Minnesota Physicians. The medication therapy management (MTM) program has grown to include 45 (30.2 FTEs) pharmacists in 54 clinic locations, 4 residents, 3 coordinators, and a leadership team that consists of the vice president of clinical services, an operations lead, MTM supervisors, and a business office manager (3.4 FTEs). Pharmacists now serve 13 specialty practices, while the rest are based in primary care clinics. In 2019, the MTM team saw 12,798 unique patients with nearly 27,000 visits. While growth has been significant, the core components of the program have remained largely unchanged. The MTM program continues its commitment to the patient care process of comprehensive medication management. ${ }^{2}$ This investment in management structures 